\title{
Schools and Moral Education: Conformism or Autonomy?
}

\section{WILLEM L. WARDEKKER}

\begin{abstract}
In pluralistic Western societies, schools have a specific task in moral education. This task is to be understood neither as the transmission of specific values, nor as the development of moral reasoning skills or universal values, but as teaching pupils to handle plurality in an autonomous way. The concept of autonomy is interpreted from a Vygotskian and Deweyan position, where learning in school means learning to participate in cultural activities in a reflective and critical way. Participation has both intellectual and moral aspects, and thus moral education can never be separated from cognitive education.
\end{abstract}

\section{UNCERTAINTY IN MORAL EDUCATION}

To judge from some rather alarming publications (for example, Ritzen, 1992), it seems that public morality and responsibility in Western countries are in danger of becoming extinct. While the more pessimistic commentators point to an increase in public excesses and vandalism, others see an increase in the number of people who base their behaviour on calculation of personal gains and losses rather than on a feeling of responsibility. Both sets of commentators, however, tend to diagnose these problems as caused by a decline in the function and importance of moral education in the family and in schools.

The causes of this decline, in its turn, are found in changes in the structure of society and the associated functions of the nuclear family. Traditional family structures are dissolving; parents are no longer the only or even the most obvious objects of identification. Their role is said to have been taken, in part, by superficially much more attractive film and television heroes, not to mention football stars. Moreover, the traditional authority of parents over their children is declining. According to De Swaan (1982), Western societies are changing from authority-based relations to negotiation-based relations. This applies to parent-child relations too.

One would expect such loss of traditional authority to lead to feelings of uncertainty in parents. This supposed uncertainty of parents has been 
the subject of many discussions. Ritzen, the Dutch Minister of Education, for instance, inferred from the decline of the traditional family and the lack of certainty in those traditional families that can still be found, that more than ever schools have a role in moral education. However, such uncertainty is not evident from a recent nationwide survey among Dutch parents in The Netherlands (Rispens, Hermanns and Meeus, 1996), or from similar data from other countries. Neither is it plausible that the number of children that are not raised within a family that contributes to the children's developing moral and cultural identity could alone account for the extent of the perceived problem.

Rather, the problem may be the development of traditional society into a plural society. By plurality, I mean not only the ever more manifest presence of ethnic groups with different cultural patterns. However much multiculturality and multi-ethnicity may occupy our attention, they are only one aspect of plurality. The wider phenomenon is that people in Western societies (and probably globally) are confronted continuously with numerous possibilities for structuring their lives and with the necessity of making choices (Giddens, 1991). It is becoming more difficult to ground these decisions in accepted rules and patterns; there is not just one authority, like the Church in earlier times, to which one can look for guidance. There is now a plethora of groups and institutions of which people may consider themselves members, often at the same time; and within them, ideals and values shift quicker and stable patterns are difficult to find, as the advertising business has found out to its chagrin.

In this situation, a traditional moral education, which emphasises loyalty to established values and points of view, becomes problematic. The unavoidable confrontation with other points of view leaves developing persons in a state of uncertainty and even possibly of anomie. This, I think, may be the background to discussions about the task and role of the schools in the moral education of their pupils.

It is significant in this context that Minister Ritzen made his plea for moral education in the schools in The Netherlands, which is characterised by a structural diversity originally based on religion. The Dutch school system was built on the idea that moral education is a prerogative of parents, and schools may only occupy themselves with it insofar they can be seen as extensions of parental authority, organised along the lines of religious denominations. State influence in moral education matters has always been viewed as suspect. Minister Ritzen, on the other hand, advocated a stronger role for schools in moral education, especially in universal values, or at least those shared widely within Dutch society. The implication seems to be that Ritzen is suggesting a way to overcome the differences in cultural points of view and values which are inherent in a plural society, thereby showing pupils a clear way to a normal life.

This plea, while on the whole received favourably, generated a lively discussion about the nature and content of values and norms to be taught in the schools. Although a few discussants took the position that 
moral education does not belong in the schools at all, most of them seem to hope that schools will be able to identify and teach at least a minimum of universal values and norms which every well-meaning person should adhere to. As an example of this, 'respect for other people and their beliefs' is often mentioned as a value of special importance in a plural society. Schools, rather than parents, are then seen as being the adequate institutions for transmitting and defending such universal values, as an extension of their task in transmitting universally valid knowledge and rational thinking and acting. For there seems to be a direct connection between rationality, right-mindedness and the 'good' life. Still others, of course, argue for a continued and enhanced function of the schools in transmitting the values of specific (religious) groups and traditions, either by themselves or as an addition to and specification of universals.

In this paper, I will examine and reject all three positions mentioned thus far. I do think that moral education is a task for schools; but neither the transmission of universal values, nor that of specific traditions, is a valid interpretation of that task. Instead, I will defend the idea that the task of moral education is to teach pupils to handle the plurality of our society in an autonomous way. This is in line with my belief that a plural society is not just to be considered a threat to morality. Rather, it presents people with opportunities and advantages over the rigid morality of traditional societies. Where everybody has the same outlook on things, and deviation is punished, often by exclusion from the community, no freedom of thought and action is possible. Such freedom is essential for finding new ways of working and living together; and finding such ways is necessary because a community that excludes change, excludes differences, will eventually become dangerously unresponsive to outside changes. This is not to say, of course, that any new way of life is better just because it is new.

\section{DO SCHOOLS HAVE A MORAL TASK?}

I will start this discussion by considering the arguments of those who would deny the school a task in moral education. Many of these arguments have been worded by the Dutch educational psychologist Hofstee (1992). His text is especially relevant because it was written as advice to the National Advisory Board on Education on the subject of the role of civic education in schools. (The Board, by the way, did not adopt the advice.) Moreover, although his actual text is limited to the situation in The Netherlands, I think his arguments have a more general application.

Hofstee's position is that schools should abstain from transmitting values and norms, except for those school rules that are instrumental in making a teaching and learning process possible. Of course, he knows that schools are actually engaged in a lot of value-transmission activities, but in his opinion this should stop forthwith. Education may teach you to use your mother language in a 'civilised' way, but it may not require you always to speak that way; it may teach about Rembrandt or Shakespeare, but it cannot require pupils actually to see them as 
beautiful. Incidentally, although he does not say so, Hofstee's ideas ultimately imply the abolishment of the present Dutch school system with its $65 \%$ of denominationally-bound schools.

Hofstee uses multiple arguments to underpin his position. First, the relationship between teachers and pupils is not of the kind required for the transmission of values and norms. Moral education calls for a personal and emotional tie, while the transmission of knowledge asks for a more objective stance. The two positions interfere with each other. Moreover, schools and teachers are geared primarily to the task of knowledge transmission; even if they want to, they hardly know how to provide for effective moral education.

Second, attitudes and values cannot be tested adequately. Even if a pupil does not demonstrate a particular moral attitude, this does not imply that no learning has taken place. Indeed, the pupil may have decided autonomously and on good grounds not to accept a particular value. And what we cannot test for, we should not try to teach, Hofstee argues. (Note that Hofstee assumes a capacity for making moral decisions, while teaching in his view is about specific values. As will become clear, in my view teaching is about creating this capacity.)

Hofstee's third argument is complementary to the second. Even if the teaching of values, norms and attitudes has the desired result, that is not something to boast of: for in fact it implies that the school has been indoctrinating pupils. It must have chosen specific values (the parents', for instance) which have been forced on the pupils. Thus, the teaching of values is contrary to the aim of attaining freedom to make your own choices in a plural world.

These arguments are not to be dismissed lightly. Indoctrination, if practised in schools (or any other context), is indeed inadmissible (Spiecker, 1991). As a consequence, Hofstee is also right in believing that it is problematical when schools adopt a specific set of values and norms, for instance those of parents or of a religious community, with the intention of inducing pupils to accept them. And finally, he is right in assuming that the results of this effort of inducing cannot be tested in any simple way. But does that really mean that all forms of moral education in schools are taboo, and moral education ought to be the exclusive domain of parental education (where, presumably, indoctrination is admissible according to Hofstee)? Hofstee certainly thinks so. In his advice on civic education in schools, he offers the alternative of a course in social psychology, which would enable pupils to foresee the effects of their actions better and thus improve their relations with other people. (The result of this learning process Hofstee calls wisdom, a term I hesitate to use in this context because of the rather instrumental nature of his intended outcome.) Of course, schools may not force pupils to apply such knowledge: for Hofstee, moral decisions are the exclusive domain of each individual.

I do not, however, agree with Hofstee on this conclusion. As I said earlier, I think that moral education in schools is not only possible, but a 
necessary element of the curriculum. But how can I uphold this opinion against the strength of Hofstee's arguments?

The problem here is that Hofstee's arguments are relevant only if we accept his tacit assumptions about the nature of moral education in schools. I interpret his position as one that holds the task of moral education to be to transfer to the pupils a set of precisely formulated values, norms and points of view. The contents of this set would depend on choices made by the school and/or parents, choices anchored in tradition. In this way, his arguments really concern the position of those who want the school to be an agent of traditional morality. And his arguments do a good job of showing why that position is problematical. In the light of what will follow here, I will add my own argument to his: an education intended to socialise pupils into rigid and pre-set, traditional patterns of norms and values does not enable them to cope with a plural society and will therefore have ever-increasing problems in legitimising itself. Moreover, it does not encourage reflection, let alone dissent, but aims for adaptation to existing values. If it succeeds, its effect will be a separation of societal groups that at best tolerate each other, but do not interact in any real moral sense. I do not think these are acceptable aims for education in schools in present society. On this point I fully agree with Hofstee.

I cannot agree, however, with another of his assumptions. This is the idea that there is a fundamental difference between knowledge and the transmission of knowledge on the one hand, and moral values and their transmission on the other. Knowledge, in the opinion of Hofstee, is value-free and has (in the ideal case) universal value. Therefore, the transmission of knowledge and abilities does not imply moral choices. (The choice of what knowledge and abilities to teach may imply moral choices; therefore, in this view such choices should be the responsibility of a democratic government.) For the pupil, then, values come into play only when the application of knowledge in action situations is called for; but schools cannot concern themselves with the courses of action pupils take in such situations. In Hofstee's view, schools prepare pupils for reallife action by giving them the cognitive instruments to act wisely; they cannot direct the actual course of action. Transmission of moral values, however, depends on moral choices, and as these are the individual's responsibility, such transmission should not take place in schools.

This difference between knowledge and values seems to disappear if we can assume the possible existence of universally valid norms and values. In that case, the necessity of making moral choices is reduced to the necessity of confining teaching to universal values. As with all knowledge, teachers might leave the legitimation of such allegedly universal values to specialists. I think even Hofstee would not object to this form of moral education in schools. And indeed, this is the course the discussion on the moral task of schools in The Netherlands has taken. After some initial hesitation, both the vice-minister of education and the president of the most prestigious advisory board have made suggestions as to which values would represent a minimum list that 
everybody could agree on and that supposedly would ensure a peaceful coexistence in a plural society (Netelenbos, 1996; Leune, 1996). Needless to say, values like 'respect for others' figure prominently on these lists.

Reaching an (even provisional) agreement on the contents of such lists would thus seem to solve the problem of the legitimation of moral education in schools. We could then go on to questions concerning the how: should we devise moral education curricula? Or should moral education be integrated somehow in other disciplines? Or should we leave it, as happens now in most cases, to extra-curricular contacts between teachers and pupils?

For the moment, I will not go into the discussion about whether the universality of such values could ever be adequately legitimised. The same problem pertains to knowledge too. There would be a lot to say about the assumption of the possibility of value-free and universally valid knowledge, as well as of universal values and norms. However, I will leave that discussion to the epistemologists for now. Here I want to concentrate on another problem, more directly related to the educational context. This is the question of whether the difference between the teaching of facts and of values would really disappear in the case of universal values. This question leads us to a discussion of the 'anthropology of learning' that is behind both Hofstee's argument and that of the 'universalists': their views of the relation between learning and acting. I will show that this is not just a discussion about the nature of teaching; it has implications for the legitimation of moral education.

\section{VALUES, KNOWLEDGE AND AGENCY}

It is a common enough idea that the task of the school is the transmission of valid knowledge, competencies and (moral) attitudes to a new generation. Education provides pupils with a stock of knowledge about the world, and with abilities they will need later on to maintain a position in that world. Normally, but (witness Hofstee) not always, values and moral rules, and the ability to make moral decisions, are considered part of this equipment not only by parents but also by teachers. Pupils will need moral rules as well as knowledge in order to live in society. In this connection it is important to note that Minister Ritzen's initiative met with a lot of agreement from teachers. Evidently they too are somewhat at a loss as to what the right or most useful rules and values would be for a future society in which their present pupils will have to live.

Two elements are important in this view. First is the necessary trust in the validity of knowledge, procedures and values, which implies they should be learned 'as given' and leaves no room for personal interpretation by pupils. Every cognitive question has one right answer; and in the same way, moral questions can be decided by reference to accepted values, be they the values of a specific cultural group or values that are considered universally valid. The emphasis on validity, which implies all pupils are to learn the same things, means that schools have a 
task in the formation of personal identity only insofar as this is a group identity; pupils are taught to adhere to the values chosen by the school management. Differentiation according to the preferences the pupils themselves have is foreign to this model. The model stresses performance, in the sense of (measurable) adherence to the 'right' answers in all activities. The consequence is that every person is seen as a separate individual in competition with all others: the best position in this competition is held by that person who has obtained the most and best resources (knowledge and abilities). Also, every person is understood as a calculating citizen, out to attain his or her own ends by a precise calculus of possible courses of action and their consequences. Morality is then mostly reduced to a number of rules that should limit the courses of action that are open, on the grounds of ill effects for others, tradition or taboo, or other types of conviction. It is what forces us to take the social context of our actions into account.

The emphasis on preparation means that the school places pupils 'in limbo' and effectively denies that they are already participating in society. School is a 'social moratorium', a place where pupils are 'fitted out' before being turned loose on the world. The idea behind this is that you first need to know a lot of things before you can rationally participate in social activities. Thinking comes before action, and in order to think you need to know.

In earlier years, this way of thinking led schools to expect a quite literal passivity on the part of pupils: be still and listen. Nowadays, pupils are expected to acquire the necessary knowledge, abilities and values in an active and often independent way, for instance by looking for information in knowledge centres, encyclopedias and the Internet. This is a less teacher-centred way of thinking, in which direct transmission is replaced by the construction of co-ordinated 'maps of the world' by the pupil. The development of such maps is dependent not only on the information available, but also on reasoning abilities that develop according to age-related stages as suggested by Piaget for the cognitive domain, and by Kohlberg $(1981,1984)$ for the moral domain. The educational consequence is that information should not be forced on pupils, but they should be allowed to discover the world and construct their cognitive maps stimulated by a 'rich environment'. Thus, 'transmission' is an inadequate description of what happens in classrooms: 'construction' is what education is all about. Pupils are, however, never supposed to participate in the construction of knowledge itself, let alone of values; they just construct their own images of preexisting knowledge. The test is still whether they can come up with the 'right' answers.

However, many educationists more or less intuitively take the position that in the case of learning norms and values this model is too restrictive in not allowing for a personal contribution by the pupil. As an example of this position, I quote from the introduction of a recent book by Klaassen in which he tries to chart the terrain of values education: 
Opinions differ on the ways in which values education can be structured as to its form and content. What people agree about is that education for norms and values is complicated. Other than in the case of the transmission of knowledge and insight, these are not educational processes in which certain contents are just transmitted and which can be evaluated and measured in a relatively exact way. Values and norms form a complex terrain of the construction of personal sense, of principles that give meaning to the life and co-existence of people and rules that regulate interactions between humans. (Klaassen, 1976, p. 7; my translation)

It is exactly this supposed difference that leads Hofstee to take his position that schools cannot concern themselves validly with the development of a moral sense in pupils. While knowledge (in intention, at least) describes the world outside us in an objective way and does not admit any constructive activity by the pupil, values are interpreted as being subjective, or at least as in need of a personal acceptance which goes beyond recognising them as objectively valid. Knowledge 'maps' belong to the cognitive domain; norms and values are related to the development of personality, and pupils must make their own choices here rather than unthinkingly accept the choices of others. In our society, we value personal development that results in autonomous agency. It is for this very reason that the question of whether schools can contribute to this development process becomes difficult to answer: can schools be seen as a place for individual self-realisation? Autonomy is not something schools can transmit, or that pupils can show in a test. For Hofstee, this apparent contradiction is a reason not to admit personality development as a valid aim of education. Kohlberg, who sees the attainment of autonomy as a developmental stage where norms and values have been internalised, thinks schools can help pupils in this development by offering a positive 'moral climate' where reasoning about moral questions is stimulated. Others have suggested didactic forms like 'values clarification'.

I do not think that we are now in a position to make an informed choice between these positions. For there is still a fundamentally unclear element in both concerning the relation between values as communal 'goods' and as personal choices. In the next section, I will develop this problem into a different view of what education is about.

\section{TWO TASKS FOR EDUCATION?}

In the last section, I discussed two positions on the subject of values education. One conceives of it as not very different from education in knowledge and cognitive insights; the other sees the two 'tasks of education' as fundamentally different. What, exactly, is the difference in points of view that these positions are based on? Superficially, the second position seems to interpret values education as a form of personality development, making the first look suspiciously like a 
form of indoctrination. Alternatively, the first can be interpreted as emphasising (even creating) unity in society, while the second values diversity and differences in choices between persons. However, I think a third interpretation is preferable, which reduces the difference to a problem of contextualisation. On this interpretation, the first position thinks of values and norms as abstract, decontextualised entities, just like knowledge is decontextualised; and thus, like knowledge, they can be transmitted 'for later use'. At that later moment, the pupil will need to contextualise the abstract rules and concepts, which presumably entails personal choices as well as rational conduct; but making such choices is not something pupils are to be prepared for and is possibly seen as something everybody can do 'naturally'. The second position, on the other hand, emphasises precisely the contextualised use of values, when pupils in a concrete situation need to make choices as to a specific course of action, and therefore sees values as belonging in the domain of personal sense-giving, but it does not deny that this sense may be based on a more general rule or concept. The difference now looks more like a question of timing than of principle.

But from the point of view of teaching and learning, this is not an innocent difference. Indeed, the question whether one can learn to act wisely by being taught general guidelines and facts is fundamental for education. The positive answer constitutes the first position, characteristic of traditional thinking about education and strongly based on rationalism, where rationality is interpreted narrowly as the autonomous ability (and the will) to make adequate ends-means connections and to act upon these. It represents a classical view of education which sufficed as long as more or less stable societal structures assured that assistance in personality development was seen as a task for and by the family and other institutions. In our present less stable society, however, it becomes evident that personality development is not natural, but is a social learning process, which moreover becomes more important as living in such a society becomes more and more dependent on a 'reflexive selfidentity' (Giddens, 1991). This position, however, in fact denies that schools have a task in assisting children to develop such an identity, and therefore it seems unsuitable in present conditions. (I will repeat here that this way of thinking also rests on the assumption of the existence of universal knowledge and values, an assumption which would merit a discussion in itself.)

The second position, on the other hand, asserts that being able to act adequately depends both on the availability of knowledge and on personality development, the latter being a matter of having acquired a certain self-identity in which norms and values have become 'your own'. Thus it seems to acknowledge the necessity of identity development. In educational practice, it is much more common than the first position: many schools and teachers see themselves as having a twofold task, one side concerned with the transmission of knowledge and skills, the other with their pupils 'as persons'. This position, however, has problems of its own. It is a strange hybrid that assumes the co-existence of two totally 
different types of learning processes: one concerned with decontextualised knowledge, the other with contextualised values and personality development. Creating the right connections between knowledge and values at the appropriate moment is a task left to pupils. The model, moreover, assumes the existence of 'value-free' knowledge and the possibility of discriminating in every instance between knowledge and values. This assumption, though sometimes thought basic to modern social science, may be difficult to substantiate.

The problems with both models, it turns out, are not problems of values education or personality development as such. Rather they are problems of the relation between moral education and the transmission of knowledge and skills. I suggest that such problems disappear when we think of the acquisition of 'knowledge and skills' in terms not of transmission, but of transformation.

\section{PLURALITY AND TRANSFORMATION}

The transformation model has grown out of the classical Bildung model with the help of the development theories of Vygotsky. In many respects it also profited from the views on education and democracy of John Dewey. This model interprets human beings not as natural or rational, but as social, beings. Social life is considered constitutive of the possibility of action. All human actions are socially situated and structured, even if at the moment of action no other persons are actually present. As a consequence, the aim of education is formulated as that of enabling humans to participate in socially, societally and culturally structured and situated activities. And learning means being enabled to participate in activities in an ever more adequate and competent way (cf. John-Steiner and Mahn, 1996). However, what is learned is not just elements of knowledge and ability. Neither can it be described as gaining the competence to act in accordance with the objective properties of the world. This is not a constructivist, but a culturally constructivist, theory: we do not act in the world as such but within socially and culturally constructed activities, and therefore the task of learning is to construct a view of these activities and your own place in them. Construction characterises both the individual and the social level of development.

In individual learning, the contents of the school curriculum are only a starting point. The pupil needs to make these contents into a part of the image she builds of concrete activities and her own position and possibilities within these in relation to other participants. Curriculum contents need to be transformed into the personal 'property' of the pupil, into 'personal knowledge' (in the sense of Polanyi, 1958). The perspectives on the world and on actions that are the outcome of this construction process are different for each individual - and it is these differences that keep a culture alive (Bruner, 1996). A perspective is not an objective cognitive map of the world or of objective possibilities for action. It is integrated with other aspects of personality like motivation, preference, valuation and moral views. In such a perspective, there is no boundary 
between 'objective' and 'valuated' components. In fact, the construction of such perspectives is part of the task of identity formation.

I want to draw special attention to the fact that learning is not about possible or future participation in activities, but about actual activities. Two consequences of this are important in speaking of the moral task of schools. First, it does not make much sense to limit this task to the teaching of universal values, even assuming these can be found. For (just like 'universally valid' knowledge) such universal values are by necessity decontextualised. There is then a distinct danger they will be memorised, will maybe even function in abstract moral reasoning, but will not actively function in concrete contexts of action. As soon as we try to contextualise them, the characteristics of that context come into play: values need to be interpreted, and lose their universality. Take the example of 'respect for others'. If this value is considered in classroom discussion in general terms only, there is a risk pupils will see no connection with their bullying of classmates. If one wants to show what it means in an actual activity setting, it will turn out that what one person calls respectful behaviour may be for another a matter of the utmost disrespect. This probably holds true for the lists of desirable values formulated in the discussion in The Netherlands.

The second point is that learning to participate in socially structured activities, including the normative elements of participating, is without doubt done best by participating in those same activities in a guided way. In fact, it is probably best to conceive of school as a place defined by this learning to participate. If we think of it that way, it becomes clear that, normally, the dominant activity in which pupils learn to participate is 'being-in-school'. Most pupils learn very fast what is expected of them, how to survive with minimum costs and other school-related skills. If, as is often the case, explicit moral education is restricted to maintaining the school rules, this serves to reinforce the idea that school does not have a purpose beyond itself. The transformation model thus calls for a restructuring of school activity in such a way that it represents the essential moments in worthwhile social activities that go on outside the school, including their normative and moral elements. School is, or at least it should be, not only about books; it is about life.

I will not go into the general consequences of the transformation model here, but concentrate on the opportunities for moral education it offers. It will be clear from the above discussion that in learning to participate, cognitive and moral learning cannot be separated. In an effective learning process, a cognitive, affective and moral bond is created between pupils and practices. This is, in fact, another way of saying that education is an enculturation process: pupils become members of the culture by participating in it.

\section{PLURALITY, PARTICIPATION AND AUTONOMY}

The above formulation which sees education as an enculturation process appears to contradict the notions from Critical Theory introduced 
before. Indeed, if education is confined to learning to participate in preselected social activities, there is a risk that pupils will only learn to adapt to accepted ways of thinking and acting within those activities. These accepted ways may never be taught explicitly; by participating, pupils may adopt values and views without thinking, without being conscious of them: participation has a strong 'hidden curriculum'. This implicit acceptance, however, can never be the aim of education in a plural society; it would in fact imply a form of indoctrination. How can the transformation model handle plurality? Can it accommodate the idea of (moral) autonomy?

The transformation model states that learning is not the same thing as accumulating knowledge and skills. It is about making sense of those elements, a sense that depends on the personal position and possibilities of the learner. In this activity of making sense, cognitive, moral and affective dimensions become one. The sense somebody attaches to participating in an activity does not coincide with his or her role or position in that activity; it is an interpretation of that position in the context of the whole activity, and in relation to other activities one participates in. This interpretation differs from person to person; and these differences are one source of change in the activity itself. Thus, the concept of transformation does not only mean that knowledge is transformed into personal sense. It also means that learners engaging in this process of sense-making are transformed themselves: by transforming their outlook on the world they are changing their identities. And moreover, activities are transformed by the participation of persons with different interpretations.

Now such transformations in personal identity and in the character of social activities may remain haphazard and chance products of learning and participation. But human beings can also try to consciously change themselves and their world. We can, to a certain extent, become coauthors of our own identity and of the cultural practices we participate in (cf. Harré and Gillett, 1994). This requires that we become conscious of our interpretations of the world, and of the values and points of view that direct our actions. Participation and reflection are not mutually exclusive: they belong together. This implies that schools should encourage a reflective way of participating in activities, including reflection on the moral side of activities. In critical reflection, knowledge, values and morals may be scrutinised and compared. This makes it possible also to generalise values and rules to other practices, to re-contextualise them.

A plural society, because of its possible clashes between points of view, offers many opportunities to start a process of reflection. Every member of such a society participates in multiple communities. These may be more or less alike, but there may also be rather sharp differences between them. (There is no real need to assume, as many do (cf. Halstead, 1996), that there must be some minimum set of values that all communities within a given society share. Rather, there will be 'family likenesses' where $A$ is like $B$ in some respects, and $B$ is like $C$ in other 
respects, without the implication that $A$ and $C$ must have something in common too.) These differences may cause conflicts. Although this does not make life easy, such conflicts can become starting points for reflection on the differences between different communities, or between ourselves and others, or even between different loyalties and different points of view in our own thinking. Reflecting and valuing differences may lead to conscious transformations in our thinking, even in our identity, and in the way we participate in activities.

Within this model, then, we would call an 'autonomous person' somebody who, when co-operating with others, is able to defend his or her actions and the values and points of view that guide it, but is also willing to reflect critically on them. It is somebody who contributes to the maintenance of rules but also to their changing and to the creation of new rules. It is somebody who is dedicated to something, but is also able to change principles if necessary. The autonomous person is always learning and contributing to the learning of others, both cognitively and morally. He or she is a conscious co-author of his or her own biography and of the history of social groups and cultural practices in which he or she participates. Sometimes these changes may be convergent, in the sense that more unity between groups, or between various points of view within the same person, is reached. But at other times divergence may be called for. Achieving personal identity does not necessarily mean that all elements of thinking, all opinions held, must become consistent with each other. Identity is never completed; its formation is a lifelong project, in which at every moment a balance must be struck between continuity and change (cf. Harré and Gillett, 1994). In a rapidly changing and plural society, a person who never changes and is totally consistent over time, a person who holds on to once-adopted points of view and does not test them against the ideas of others, is someone who becomes fossilised and in fact contributes to the fossilisation of society into separate groups that at best tolerate each other, but do not learn from each other.

This view of autonomy differs from that of Kohlberg in that it does not refer to a formal reasoning ability, or any other telos of development inherent in reality, but to a contextualised way of participating in social activities. Also, it does not necessarily apply to all terrains of life at the same time. One may function in an autonomous way in some respects, and in a heteronomous way in others. And finally, autonomy is not reached as the result of a more or less automatic development. It has to be learned, and schools can make an important contribution to this learning process, even though it may not be the kind of learning process that parents, or governments, expect.

This brings us back to the earlier problem of a continuity in moral outlook and practice between the home and the school. I think that as a starting point, such continuity (as, for instance, indicated in the 'mission statement' or the denominational adherence of a school) may be important. If the moral climate in school initially differs too much from that in the home, pupils may be at a loss and feel unsafe, with 
detrimental results for both moral and intellectual development. But the above discussion leads me to stress two points. First, the 'moral quality' of a school is not restricted to, or even primarily about, life in school. It is about the way pupils are taught to participate in cultural activities. We should not expect automatic transfer from the practice of beingin-school to other practices. Such 'transfer' is effected only through reflection and the development of autonomy. Second, reflection and autonomy need a confrontation with other practices, other possibilities. A school that adheres strictly to a chosen set of values, that does not admit plurality, is one that impedes the development of autonomy.

Correspondence: Willem L. Wardekker, Department of Education, Free University of Amsterdam, Van der Boechorststraat 1, 1081 BT Amsterdam, The Netherlands. E-mail: wl.wardekker@psy.vu.nl

\section{REFERENCES}

Bruner, J. (1996) The Culture of Education (Cambridge, MA, Harvard University Press)

De Swaan, A. (1982) De mens is de mens een zorg [People are a concern to people] (Amsterdam, Meulenhoff)

Giddens, A. (1991) Modernity and Self-identity. Self and society in the late modern age (Cambridge, Polity Press)

Halstead, J. M. (1996) Values and value education in schools, in: J. M. Halstead and M. J. Taylor (eds) Values in Education and Education in Values (London, Falmer)

Harré, R. and Gillett, G. (1994) The Discursive Mind (Thousand Oaks, CA, Sage)

Hofstee, W. K. B. (1992) Een curriculum voor burgerschap [A curriculum for citizenship], in: H. R. van Gunsteren and P. den Hoed (eds) Burgerschap in Praktijken, I, 257-279 (Den Haag, SDU)

John-Steiner, V. and Mahn, H. (1996) Sociocultural approaches to learning and development: a Vygotskian framework, Educational Psychologist, 31, 191-206

Klaassen, C. (1996) Socialisatie en moraal. Onderwijs en waarden in een laat-moderne tijd [Socialisation and morality: education and values in late modernity] (Leuven/Apeldoorn, Garant)

Kohlberg, L. (1981, 1984) Essays on Moral Development 1 \& 2 (San Francisco, CA, Harper \& Row) Leune, H. (1996) Over de normatieve taak van de school [On the normative task of the school]. Paper for Congress 'Onderwijs, moraal en burgerschap', Nijmegen, 11 June

Netelenbos, T. (1996) Untitled paper for Congress 'Opvoeding, Onderwijs en Sociale Integratie', Amsterdam, 17 and 18 October

Polanyi, M. (1958) Personal Knowledge (London, Routledge \& Kegan Paul)

Rispens, J., Hermanns, J. M. A. and Meeus, W. H. J. (eds) (1996) Opvoeden in Nederland [Upbringing in the Netherlands] (Assen, Van Gorcum)

Ritzen, J. M. M. (1992) The moral task of education. A call for joint action (Zoetermeer, Netherlands Ministry of Education and Science)

Spiecker, B. (1991) Indoctrination: the suppression of critical dispositions, in: B. Spiecker and R. Straughan (eds) Freedom and Indoctrination in Education. International Perspectives (London, Cassell) 